\title{
Briefing notes on maritime teledermatology
}

\section{Eilif Dahl}

Department of Occupational Medicine, Haukeland University Hospital, Norwegian Centre for Maritime Medicine, Bergen, Norway

\begin{abstract}
All coastal states must provide telemedical assistance services (TMAS) $24 h$ a day free of charge to all ships. Skin lesions account for many urgent TMAS consultations, but may be difficult to describe for seafarers without much medical training - and even for medical personnel on cruise ships. By following simple instructions provided in this article, good photographs - taken by digital cameras or smart phones and transmitted by e-mail to TMAS - can compensate for imprecise descriptions. The on-line TMAS physician can then easily consult with a dermatologist if necessary.

Highly specialised teledermatology services are commercially available for cruise companies. Their ship's doctors thereby get prompt access to expert medical opinion without the time, logistical issues and costs associated with seeking dermatologic care ashore. Teledermatology allows cruise medical staff to effectively manage skin conditions aboard and limits unnecessary dermatology clinic referrals. For the ships' medical staff the teledermatology service is also an opportunity for continuous education which may benefit skin patients aboard in the future.
\end{abstract}

(Int Marit Health 2014; 64, 2: 61-64)

Key words: telemedical assistance service (TMAS), teledermatology, clinical photography, digital photo transmission, cruise ships

\section{INTRODUCTION}

Skin conditions are frequent concerns of seafarers [1]. Skin disorders ranged second and third of the most important groups of diseases in a large survey among Polish fishermen and seafarers, respectively [2]. Hence, it is hardly surprising that a substantial part of advice requests from ships to land based telemedical assistance services (TMAS) regards skin conditions [1].

Based on telemedical case logs, Lucas et al. [3] found that $10 \%(183 / 1844)$ of calls that required acute treatment were due to skin disorders and that 'in some cases digital photographs helped in the diagnostics'.

In two world cruise studies, the most frequent reason for crew visits to the ships' medical centres was skin conditions; they accounted for $29 \%$ and $27 \%$ of the crew consultations, respectively $[4,5]$. Although none of these visits resulted in crew referrals to port dermatologists, such referrals are nevertheless so common that one large cruise corporation in 2010 decided to introduce teledermatology on the vessels [6]. Instead of referring a passenger or crew member to a dermatologist in a port of call, the ship's doctor must first consult with the company's contracted teledermatology service.

\section{TELEDERMATOLOGY}

Teledermatology is dermatologic care given to patients where and when it's needed using telecommunication technologies to exchange medical information over a distance [7]. On land it is a well-established dermatology subspecialty and probably one of the most common applications of telemedicine and e-health. It is practiced on the basis of two concepts: store and forward and real time/live interactive teledermatology. Hybrid modes also exist (combining store and forward and real time applications). The store and forward method is most commonly used in teledermatology: It involves sending (forwarding) digital images associated with (anonymous) medical information to the data storage unit of a consulted specialist. It can be as easy as sending an e-mail with a digital image of a lesion to seek advice for a skin condition. Advantages of this method are that it does 
not demand the presence of both parties at the same time and does not usually require expensive equipment [7]. It can be useful for patient filtering and triage (i.e. referral based on the severity and character of their skin condition) and to limit unnecessary dermatology clinic referrals, as well as provide diagnoses, treatment suggestions and follow-up [8].

\section{TELEDERMATOLOGY AT SEA}

International commercial shipping comprises 55$-65,000$ ship with more than 1.2 million seafarers who at times may be in areas where telemedical services may be necessary, and it has been estimated that worldwide there are more than 120,000 telemedical consultations a year [9]. According to The Maritime Labour Convention (MLC) 2006, all coastal states must provide medical advice by radio or satellite communication to ships at sea, including specialist advice, available $24 \mathrm{~h}$ a day free of charge to all ships irrespective of the flag that they fly [10].

When TMAS is needed, the ship's officer responsible for crew care aboard, usually the captain or the first mate/ /chief officer, will contact the TMAS doctor on call. For skin conditions the TMAS doctor will usually ask for photos in additional to a brief description of the lesion and a medical history. Most vessels now have a high quality digital camera, and even new-generation mobile devices (smart phones) can be used to take good enough photos to be transferred as attachments to encrypted e-mail [11].

In Norway, TMAS is run by the Norwegian Centre for Maritime Medicine, which is located at and part of Haukeland University Hospital in Bergen. It responds to requests for medical assistance from ships all over the world, regardless of flag state (contact information: www.ncmm.no, see Radio Medico/Medical Advice). If the TMAS doctor wants a second or expert opinion, he or she can use the university hospital's resources and forward the information and photos received from the ship to any of its specialists on $24 / 7$ call, including the dermatologist.

Urgent teledermatology consultations might be considered in cases with rapid onset, when there is a widespread rash, or the rash is on the face, hands or genitals, if there is fever, severe itching, pronounced pain, blisters or swelling, or when decisions regarding isolation or medical evacuation must be made. Less urgently TMAS can be contacted for dermatologic diagnosis, treatment suggestions and follow-up of progression and/or treatment effect. On merchant ships without a doctor, the options for dermatological therapies are rather limited on board $[12,13]$, but most skin lesions will heal with simple remedies.

\section{RELEVANT TELEDERMATOLOGY DATA}

Although good photos in skin cases say more than many words, additional written information may give better results. Hence, as much of the below data as possible should be forwarded in each case:

- Demographics: Identification number (passport, seafarer book, or company employee number), name, age, gender, occupation aboard and skin colour (race/ /ethnicity).

- History: Chief skin complaint or symptoms, time of onset and duration, aggravating and/or alleviating factors, known allergies, recent exposures and drugs/medication.

- Description: Type and number of lesions, size [mm], surface, shape, borders (sharp/diffuse), colour, distribution and location. Scratch marks? Table 1 gives some examples of dermatology definitions and terminology [14].

- Location and distribution: It is important to note whether lesions are single or multiple; particular body parts are affected (e.g. palms or soles, genitals, scalp, mucosal

Table 1. Some common descriptive terms for skin lesion types according to morphology, colour, surface and size [14]

Rash is a general term for a temporary skin eruption.

Macules (maculae) are flat, non-palpable discoloured lesions $<10 \mathrm{~mm}$ in diameter and not raised or depressed compared to the skin surface. A patch is a large (>10 $\mathrm{mm})$ macule.

Papules are elevated lesions $<10 \mathrm{~mm}$ in diameter that can be felt or palpated; papules may become confluent and form plaques. Plaques are circumscribed, superficial, elevated, and solid (palpable) lesions $>10 \mathrm{~mm}$ in diameter.

Nodules are firm, elevated lesions $>10 \mathrm{~mm}$, and larger nodules are referred to as tumours.

Vesicles are small, clear, fluid-filled blisters $<10 \mathrm{~mm}$ in diameter, while bullae are clear fluid-filled blisters $>10 \mathrm{~mm}$ in diameter, and pustules are vesicles that contain pus.

Urticaria (wheals or hives) is characterised by elevated lesions caused by localised oedema. Wheals are itchy and red and typically last $<24 \mathrm{~h}$.

Scale is heaped-up accumulations of horny skin cells, while crusts (scabs) consist of dried serum, blood, or pus.

Petechiae are nonblanchable punctate foci of haemorrhage, and purpura is a larger area of haemorrhage that may be palpable.

Atrophy is thinning of the skin, which may appear dry and wrinkled, resembling cigarette paper.

Scars are areas of fibrosis that replace normal skin after injury, and keloids are thickened and raised (hypertrophic) scars that extend beyond the original wound margin. 
membranes); lesions are on sun-exposed or protected skin; and whether distribution is random or patterned, symmetric or asymmetric.

\section{BASIC CLINICAL PHOTOGRAPHY}

Proper description of skin lesions is difficult for officers without much medical training, but good photos can compensate for imprecise descriptions. Below are instructions for high quality clinical photos, following guidelines from Alaska Federal Health Care Access Network [15] and University of Miami Telehealth [16]:

- General: There should be at least one regional + one close-up + one tangential view of the lesions; all well-lit and clear - in true colour and sharp focus. If palms are involved, show dorsal hands; if palms are involved, check soles; and if it is a facial lesion, take photos of full face as well as left and right sides of the face.

- Subject: The lesion should take up most of the frame and remove items that distract from the lesion. For the right perspective, keep the camera parallel to the lesion surface. For shadows, to visualise raised lesions, use lighting from the side (elevated papules versus flat macules; Table 1). Care should be taken to get the colours of the lesions right; to reproduce the true shades of red is particularly challenging. Take photos both with and without flash to see which gives the best image. Provide enough information to determine the size of the lesion. For scale, add a ruler to the photo.

- Background: Choose a solid colour background, and avoid white, black or textured backgrounds. Avoid reflective surfaces.

- Focus: Use 'Macro' for all close-ups (5-70 cm/2"-28"). Zoom can allow a closer image without being close to the lesion. But zoom magnifies camera movement, so only use it when it is really necessary. Steady the camera to avoid blur from camera movement: use a tripod, or if standing brace your elbows against your body, and if sitting place your elbows on a table and use your arms as a tripod. Gently squeeze the shutter to focus and then take the photo.

\section{TELEDERMATOLOGY ON CRUISE VESSELS}

Although national TMAS are available for free to all ships, at least one cruise corporation has contracted a commercial, highly specialised teledermatology service ashore, considering it one component of its efforts to improve health care services for ship employees and passengers [6]. Ship's doctors occasionally need to consult with dermatologists, but it is often difficult to access dermatologists for face-to-face visits during a cruise. Specialised teledermatology allows them to transmit dermatology images and information from ships across the fleet to dermatologists for remote consulta- tion, "to receive expert medical opinion in a timely manner without the time, logistical issues and costs associated with seeking care ashore" [6]. It is particularly useful for patient filtering and triage (i.e. referral based on the severity and character of their skin condition) and to limit unnecessary dermatology clinic referrals. Furthermore, it provides diagnosis or differential diagnoses and recommendations for management and follow-up. When the contracted teledermatology service is familiar with the fleet's standardised formulary, recommendations can be made based on the remedies that are available on the ships. Based on findings over time, the ships' formulary can then be adjusted to cover the actual therapeutic needs of the fleet. For the cruise vessels' medical staff the teledermatology service is an opportunity for continuous education which may benefit skin patients aboard in the future [16].

To qualify for using the contracted teledermatology service, the ship's doctor or nurse must register and complete an internet training program, comprising short (5-7 min) videos on common dermatoses, teledermatology terminology, dermatologic photography, camera operation, storeand-forward photography technique, and how to enter a consult request with the teledermatology company $[6,16]$.

The teledermatology service involves a ship's physician or nurse taking digital photographs of areas of concern on the patient's skin. These images are combined with medical history and other relevant information that are entered into a special web-based software system that uploads the case to a secure server. A consulting dermatologist reviews the case and makes his or her recommendation for a course of care to be implemented by the ship's physician. In urgent cases the ship will receive a report within $24 \mathrm{~h}$ while non-urgent or routine cases are evaluated within $72 \mathrm{~h}$. Still, the accuracy of the response depends on the quality of the input received. Teledermatology consult replies therefore start with: "Based on the history and images provided, my impression is as follows..." [16].

\section{CONCLUSIONS}

TMAS, including specialist advice, is available $24 \mathrm{~h}$ a day free of charge to all ships. Acute skin disorders account for a significant part of urgent TMAS consultations. Skin lesions may be difficult to describe for seafarers without much medical training - and even for medical personnel on cruise ships, but good photographs can compensate for imprecise descriptions. By following simple guidelines useful photograph can be taken by a digital camera or smart phone and be transmitted by e-mail to an on-line physician who can then consult with a dermatologist if necessary. This takes us another step toward the MLC 2006 goal of "providing seafarers with health protection and medical care as comparable as possible to that which is generally available 
to workers ashore' [10]. Highly specialised teledermatology services are commercially available for cruise ships with doctors aboard.

\section{REFERENCES}

1. Riis Jepsen J. Disorders of the skin. In: Textbook of maritime medicine V2 2013. In: Carter T, Schreiner A eds. http://textbook.ncmm. no (Accessed 03 June 2014).

2. Tomaszunas $S$, Weclawik Z, Lewinski M. Morbidity, injuries and sick absence in fishermen and seafarers: a prospective study. Bull Inst Marit Trop Med Gdynia 1988; 39: 125-135.

3. Lucas R, Boniface K, Hite M. Skin disorders at sea. Int Marit Health 2010; 61: 9-12.

4. Dahl E. Anatomy of a world cruise. J Travel Med 1999; 6: 168-171.

5. Dahl E. Medical practice during a world cruise: a descriptive epidemiological study of injury and illness among passengers and crew. Int Marit Health 2005; 56: 115-128.

6. University of Miami TeleHealth Provides Remote Dermatology to Cruise Ships (press release from Miller School of Medicine Departments and Centers 2/3/2011) http://www.med.miami.edu/news/ um-telehealth-provides-remote-dermatology-to-cruise-company (Accessed 03 March 2014).

7. Anonymous. Teledermatology. From: Wikipedia, the free encyclopedia. http://www.en.wikipedia.org/wiki/Teledermatology (Accessed 03 June 2014).

8. Warshaw EM, Hillman YJ, Greer NL et al. Teledermatology for diagnosis and management of skin conditions: a systematic review. J Am Acad Dermatol 2011; 64: 759-772.
9. Tveten A. Status maritim telemedicin. DoCumentum navale 2013; 51: 1-2.

10. International Labour Conference. Maritime Labour Convention, 2006. http://www.mlc2006.com (Accessed 03 June 2014).

11. Anh Duong T, Cordoliani F, Juilliard C et al. Emergency department diagnosis and management of skin diseases with real-time teledermatologic expertise. JAMA Dermatology. Published online 07 May 2014 (Accessed 25 May 2014).

12. World Health Organization. International medical guide for ships: including the ship's medical chest. $3^{\text {rd }}$ Ed. WHO, Geneva 2007.

13. Schlaich C, Reinke A, Sevenich C et al. Guidance to the International Medical Guide for Ships 3rd edition: Interim advice regarding the best use of the medical chest of ocean-going merchant vessels without a doctor onboard. Int Marit Health 2009; 60: 51-66.

14. MacNeal RJ. Dermatologic disorders. The Merck Manual for Health Professionals (Content last modified September 2013) http://www. merckmanuals.com/professional/dermatologic_disorders/approach_to_the_dermatologic_patient/description_of_skin_lesions.html (Accessed 28 March 2014).

15. Alaska Federal Health Care Access Network (AFHCAN Consult). Clinical Photography Computer Based Training Module. Alaska Native Tribe Health Consortium 2009. http://afhcan.org/training/Basic\%20 Clinical\%20Photography/index.html (Accessed 28 March 2014).

16. Burdick AE. Teledermatology at sea. Book of abstracts. Abstract \#3; page 35. $12^{\text {th }}$ International Symposium on Maritime Health, Brest France, 4-7 June 2013 (Supplemented with information from Burdick AE. Shipboard Dermatology. Lecture at RCl's International Academy of Cruise Ship Medicine, Miami, USA, 09-13 September 2013). 